\title{
Safety and efficiency benefits from using automated backfill diverter valves on Kirkland Lake Gold Fosterville mine's paste reticulation systems
}

\author{
R Evans Kirkland Lake Gold Ltd., Canada \\ G Trinker Victaulic Co., USA \\ M Carriere Victaulic Co., Canada
}

\begin{abstract}
As backfill systems become a more common method for managing tailings and enhancing ore recovery, safe and efficient methods for handling the backfill are adding value for mine owners. At Kirkland Lake Gold Fosterville mine (Victoria, Australia), automated diverter valves were installed at distribution switching points to direct paste to the intended stopes. The valves are operated remotely from a control room, removing the human element at the transition point during diversion. The other option for making changes in paste distribution is a manual operation where long sweep elbows are disconnected from the piping network and reconnected to a different downstream pipe. This process is tedious and time consuming, requiring many man hours and equipment that is not always readily available, resulting in much down time.

This paper will discuss how using automated diverter valve operation in place of manual diversion of the paste at Kirkland Lake Gold's reticulation system delivered dramatic uptime and minimised physical safety risks. Safety benefits not only eliminated the manual movement of piping components but include localised lockout access, safe evacuation of paste from upstream borehole (and piping) resulting from downstream blockage and diversion of flush water to a suitable collection area.
\end{abstract}

Keywords: backfill, paste reticulation, diverter valve

\section{Introduction}

Many mine owners around the world are using manual backfill processes that rely on experienced workers investing considerable time and effort in risk-prone processes. These methods require significant man hours and are dependent upon having skilled labourers on site, and expensive, specialised equipment on hand.

As mine owners employ different means of improving economics, many are using backfill systems to dispose of tailings and enhance ore recovery while continuously looking for safe and efficient ways to manage the backfill process. At Kirkland Lake Gold Fosterville mine in Victoria, Australia, automated diverter valves were installed at distribution switching points to improve this process, directing paste to the intended stopes without the need for underground crews and additional equipment.

The other option for directing paste to alternate stopes through distribution piping is a manual operation that involves long sweep elbows to be disconnected and reconnected to a different downstream pipe. This manual operation is time consuming, and when the necessary manpower and/or equipment is not available, results in considerable downtime.

The diverter valves address many of the issues encountered during manual operations. The valves function reliably in a broad temperature range, and valve operation does not require specialised equipment or skills. Because the valves can be operated remotely, they improve safety by reducing the risk of injury by removing people from harm's way. 
This paper examines the use of automated diverter valves to replace manual diversion of paste in the Fosterville gold mine (FGM) reticulation system. Replacing the manual process with a remotely controlled system of valves resulted in dramatic reduction in safety risks and improved uptime by enabling safe and timely switching of the reticulation route.

\section{Traditional approaches}

Most medium- and high-grade mining operations use backfill. When maintenance is required in the reticulation system or when backfill is required in a different stope, the system is shut down, and the piping is switched manually. Each time this takes place, multiple workers and equipment are involved, and the resulting downtime is significant. This manual process introduces safety risks and takes workers away from more productive activities.

\section{$3 \quad$ Introducing innovation}

Victaulic designed the Series $725 \mathrm{~S}$ diverter valve specifically for use in backfill operations. Providing multidirectional service, the valve eliminates the need for manual manipulation of backfill piping systems. Installing automated diverter valves at switching points on paste piping allows backfill to flow to alternative stopes without requiring manual manipulation of the pipe/pipe fittings to redirect flow.

Designed to withstand the high pressures of underground systems, the valve is rated to $10.35 \mathrm{MPa}(1,500 \mathrm{psi})$ and uses a 4D bend radius flow path to reduce wear from abrasive slurry and high-flow conditions. All wetted surfaces of the Series $725 \mathrm{~S}$ valve are constructed from martensitic stainless steel, which provides excellent abrasion and corrosion resistance. Continuous flushing is unnecessary as the smooth profile of the plug prevents clogging. This valve is customisable, accommodating electric, hydraulic or pneumatic actuation, and can be installed vertically, horizontally or in any intermediate position. The valve is offered with grooved, double-grooved or ringed ends, allowing the specifier to choose the preferred mechanical couplings for quick and simple installation and removal.

\section{$4 \quad$ A new approach}

Efficiency gains are being achieved by replacing manual backfill systems with methods that are faster and safer. Installing automated diverter valves in the Kirkland Lake FGM illustrates how functionality and safety can be improved, leading to time savings and ultimately better economics.

\subsection{Mine history}

FGM is approximately $20 \mathrm{~km}$ east of the city of Bendigo and $130 \mathrm{~km}$ north of Melbourne in the state of Victoria, Australia. The FGM and associated infrastructure are on Mining License 5404 , which is $100 \%$ owned by Kirkland Lake Gold Ltd. (Figure 1).

Gold was discovered in the area in the mid-1800s, and mining activity was underway by 1894 . Exploration activities by various owners of what is now the FMG ensued from 1973, with heap leaching operations from an oxide pit beginning in 1993. By 1998, Perseverance Corp., which operated the mine, was producing $40,000 \mathrm{oz} /$ year from the oxide ore. In mid-2001, a sulphide resource was developed, and an open pit was initiated in 2004. The first gold pour at the site took place in 2005. 

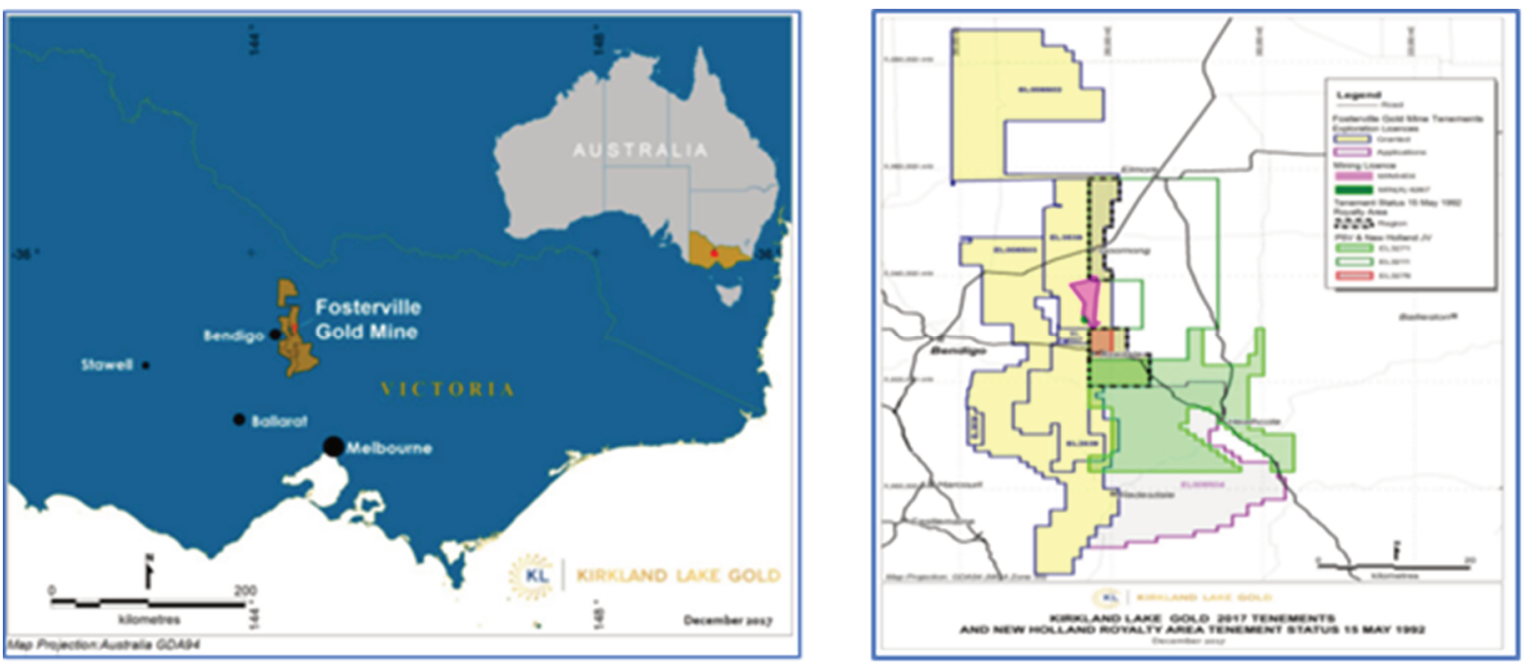

Figure 1 The Kirkland Lake Fosterville gold mine Victoria, Australia. Source: Kirkland Lake Gold, Toronto, Ontario

The owners started an underground decline in March 2006, and the first underground stope was mined in December 2006. By early 2008, underground ore had become the main mill feed.

Kirkland Lake Gold Ltd., headquartered in Canada, purchased the mine in November 2016 and began an aggressive exploration programme that yielded impressive results, including the Swan Zone, which contains $2.34 \mathrm{M} \mathrm{oz}$ at an average grade of $49.6 \mathrm{~g} / \mathrm{t}$ gold. FGM produced approximately 600,000 oz of gold in 2019 .

\subsection{Mining method}

Current mining at FGM is undertaken predominantly as owner-miner. FGM uses an open stoping, retreat mining method with the use of backfill to extract gold ore from the Phoenix decline orebodies. Figure 2 shows the actual and proposed mining layout at FGM.

Stoping widths vary as dictated by grade distribution in the block model, and strike length is determined by rock mass and hanging wall stability assessments. Once a stope has been mined out, the void generally is backfilled to ensure stability in accordance with planned future vertical and horizontal exposures. The open stopes are relatively small, ranging from 500 to $2,700 \mathrm{~m}^{3}$ with an average of $1,500 \mathrm{~m}^{3}$. The current annual backfill requirement is 100,000 to $110,000 \mathrm{~m}^{3}$ per year.

Mining method selection within the open stoping regime is based on experience, expectations of ore zone geometry, and geotechnical conditions. A standard level interval of 20 vertical metres is usually applied across all mining areas. However, this is sometimes varied to maximise extraction of the economic material. Underground mining employs a conventional fleet, including twin boom development drills, production drills, loaders, trucks, and ancillary equipment. 

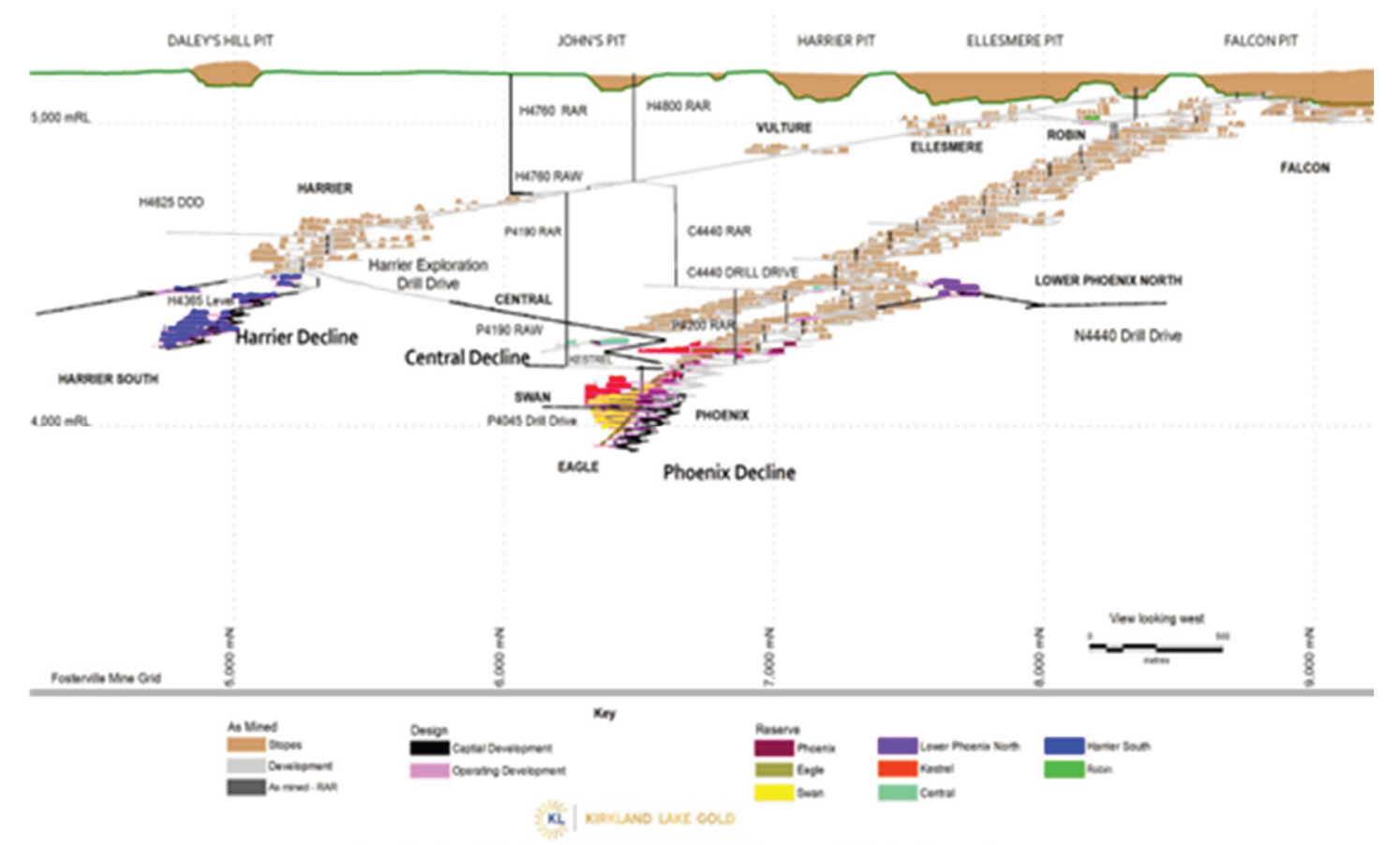

Figure 2 Actual and proposed mining layout at the Kirkland Lake Fosterville gold mine. Source: Kirkland Lake Gold, Toronto, Ontario

\subsection{Backfilling}

Historically, mining at FGM had been done top-down without backfill or with limited quantities of cemented rockfill (CRF) using underground development waste mixed with cement slurry. With the discovery of the high-grade Swan Zone, a decision was made to design and construct a paste backfill system. In the interim, while awaiting the construction of the new paste plant, the stopes would all be filled with CRF. Because of the relatively flat dipping nature of the orebody, the hanging walls required topping up with a flowable fill a mixture of various sands, cement, and water. The objective of this process was to reduce hanging wall failure. While it was effective, the backfill method was slow, and operating costs were high.

The decision to switch to paste backfill was based on ensuring that the backfill achieved full confinement of hanging wall voids; leading to higher productivity, lower dilution, and reduced operating costs.

The paste plant process design combines full plant tailings and binder at a rate of $65 \mathrm{~m}^{3}$ per hour. The paste plant dewatering circuit includes a thickener and two large vacuum disc filters. These feed a continuous mixer where binder and water are added to the filter cake to produce paste with the required slump or yield stress. Lime may also be added during this process when required.

The paste plant location allows the paste fill to flow by gravity to the Phoenix ore zones. The paste is delivered through a 1,040 m deep borehole from the surface paste plant to underground level P4190L. The 7 5/8" $(193.7 \mathrm{~mm}$ ) steel casing in the borehole is lined with a $12 \mathrm{~mm}$ ceramic epoxy polymer coating. The borehole casing has an ID of $150 \mathrm{~mm}$. Figure 3 shows the paste reticulation long section at FGM. 


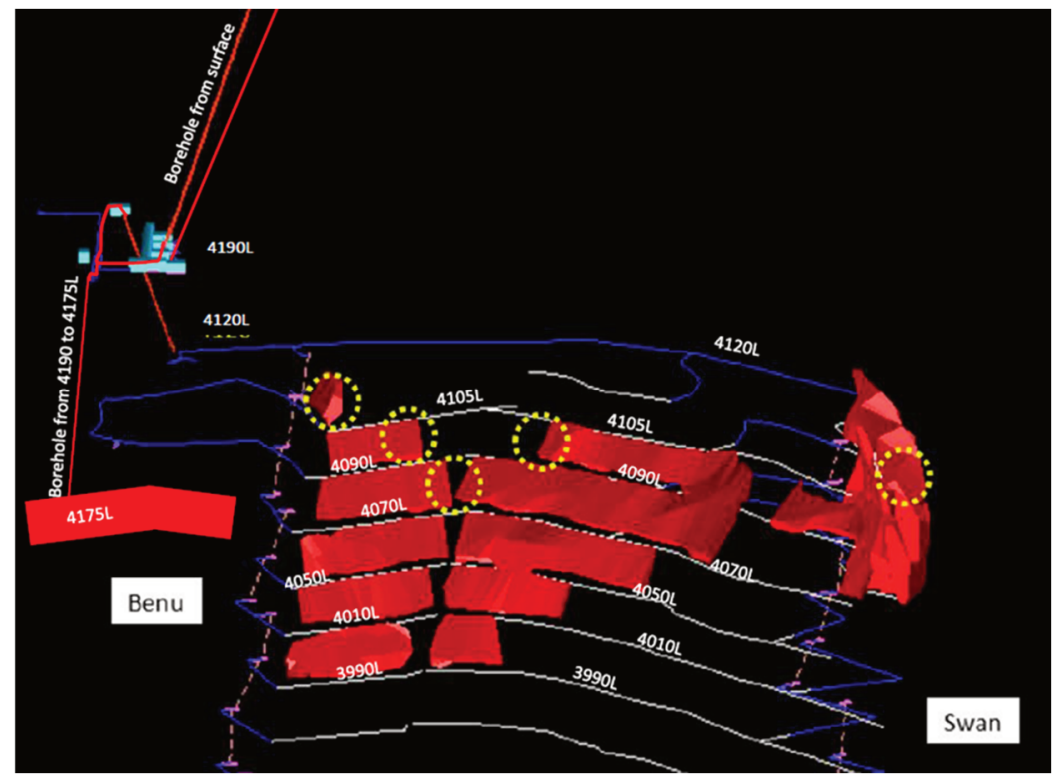

Figure 3 The paste reticulation long section at Fosterville gold mine. Source: Kirkland Lake Gold, Toronto, Ontario

\section{Implementing automation}

The current paste reticulation system is made up of 150NB Sch80 ASTM A106B SMLS pipe connected with Victaulic HP-70ES couplings. The pipe spool lengths include $6 \mathrm{~m}, 3 \mathrm{~m}, 1 \mathrm{~m}$ and $300 \mathrm{~mm}$ straight lengths as well as Victaulic cast 3D bends of 90, 45, 22.5 and 11.25 degrees. The hanging and thrust support are galvanised steel.

The reticulation system includes pressure sensors and pressure relief spools on each level, a flow meter on level P4190L and a dump valve at the base of the main borehole. There are permanent closed-circuit television (CCTV) cameras at two locations on level P4190L. Portable CCTV cameras are positioned at the pour point for each stope and at the fibrecrete bulkheads on the undercut of each stope. Total earth pressure cells and piezometers are installed inside most bulkheads. Workers monitor the instrumentation and CCTV cameras in real time from the control room at the paste plant.

A trade-off study was done to evaluate the benefits of using actuated diverter valves versus manually changing the direction of pipe spools when switching the pour locations.

The relatively small stope volumes averaging only $1,500 \mathrm{~m}^{3}$ of paste was one of the factors that contributed to the decision to implement the use of diverter valves. Based on the stope volumes and the production rate of $65 \mathrm{~m}^{3}$ per hour, reticulation changes would be required at least once per day and possibly two times per day.

The decision was made to use remotely actuated diverter valves based on improved safety, higher productivity, and lower operating costs.

The Victaulic 725S diverter valve was selected from among the various diverter valves available on the market based on design and price. 


\subsection{Fosterville diverter valve installation detail}

The Victaulic 725S diverter valves at FGM are equipped with $415 \mathrm{~V}$ electric actuators, limit switches and Auma remote control units. Pneumatic actuators had been considered to reduce capital costs; however, they would have still required an electrical source to actuate solenoids and power limit switches, in addition to the requirement for an air supply system. It was therefore decided that electric actuators would be the most suitable as they would use the existing electrical infrastructure used to power pressure sensors, CCTV cameras and other equipment. Underground power supply at FGM is $1,000 \mathrm{~V}$. Transformers reduce the voltage to operate equipment.

Paste boards were designed for each level. These boards included the transformers to reduce $1,000 \mathrm{~V}$ to $415 \mathrm{~V}, 240 \mathrm{~V}$ and $24 \mathrm{VDC}$ to power all the equipment and instrumentation, and communications equipment to connect them to the surface programmable logic controller (PLC).

Each diverter valve has a unique number in the PLC control logic while each discrete paste line is identified by a pipeline number. These numbers are physically displayed on the diverter valves inlet and outlets and on the attached pipelines.

\subsection{Diverter valve operation}

The paste fill note includes instruction for the setup of each diverter valve for each pour (Figure 4). The instructions indicate the required direction for each diverter using the diverter valve number and identifies the specified direction of flow to either the A or B outlet, including the paste line number for the outlet.
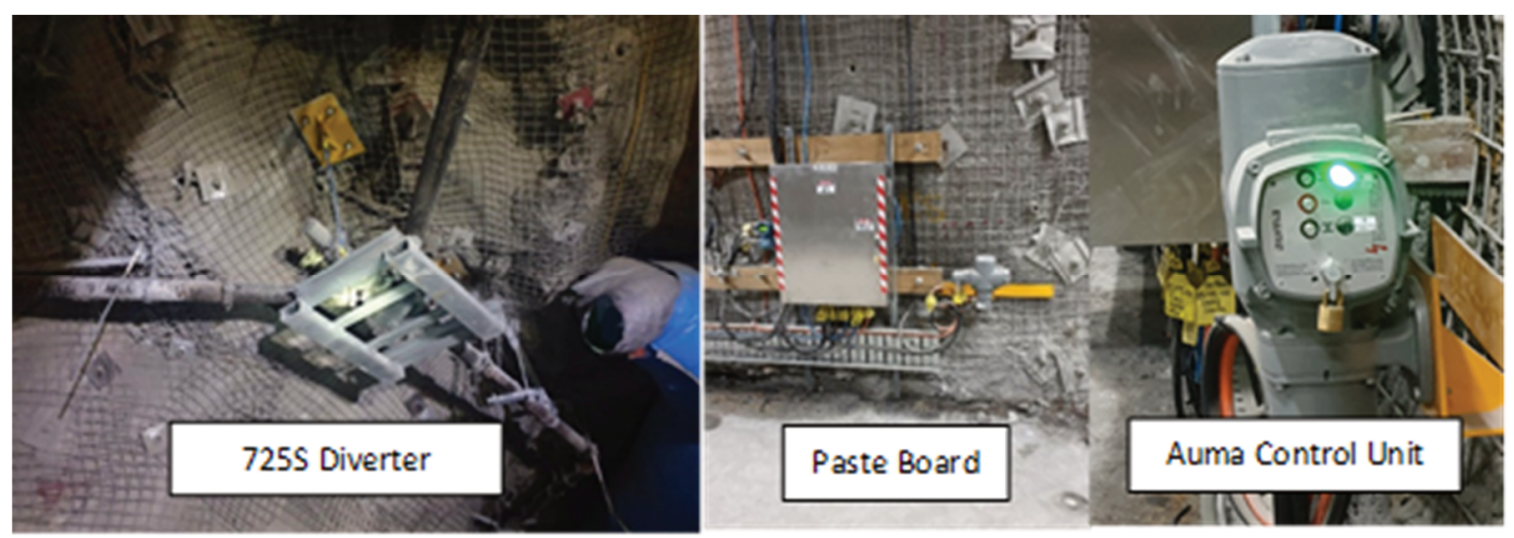

Figure 4 The paste fill note includes instructions for setting up each diverter valve for each pour. Source: Kirkland Lake Gold, Toronto, Ontario

The paste fill note is delivered to both the surface paste plant operator and the underground paste operator. The surface operator switches the valves to the required positions on the human-machine interface (HMI) and advises the underground operator that the valves are correctly positioned. The plant operator can see the piping route highlighted in blue on the HMI display. The colour changes from blue to red when there is pressure or flow in the line (Figure 5).

Using the paste fill note, the underground paste operator checks all the pipes along the route to the stope, including the diverter valves. By consulting the diverter valve instructions in the note, the underground paste operator ensures the yellow indicator on the valve is pointing towards the correct line number indicated in the note. Once confirmed, the underground operator switches the diverter control panel to the local mode so the direction of the valve cannot be changed during pouring. 


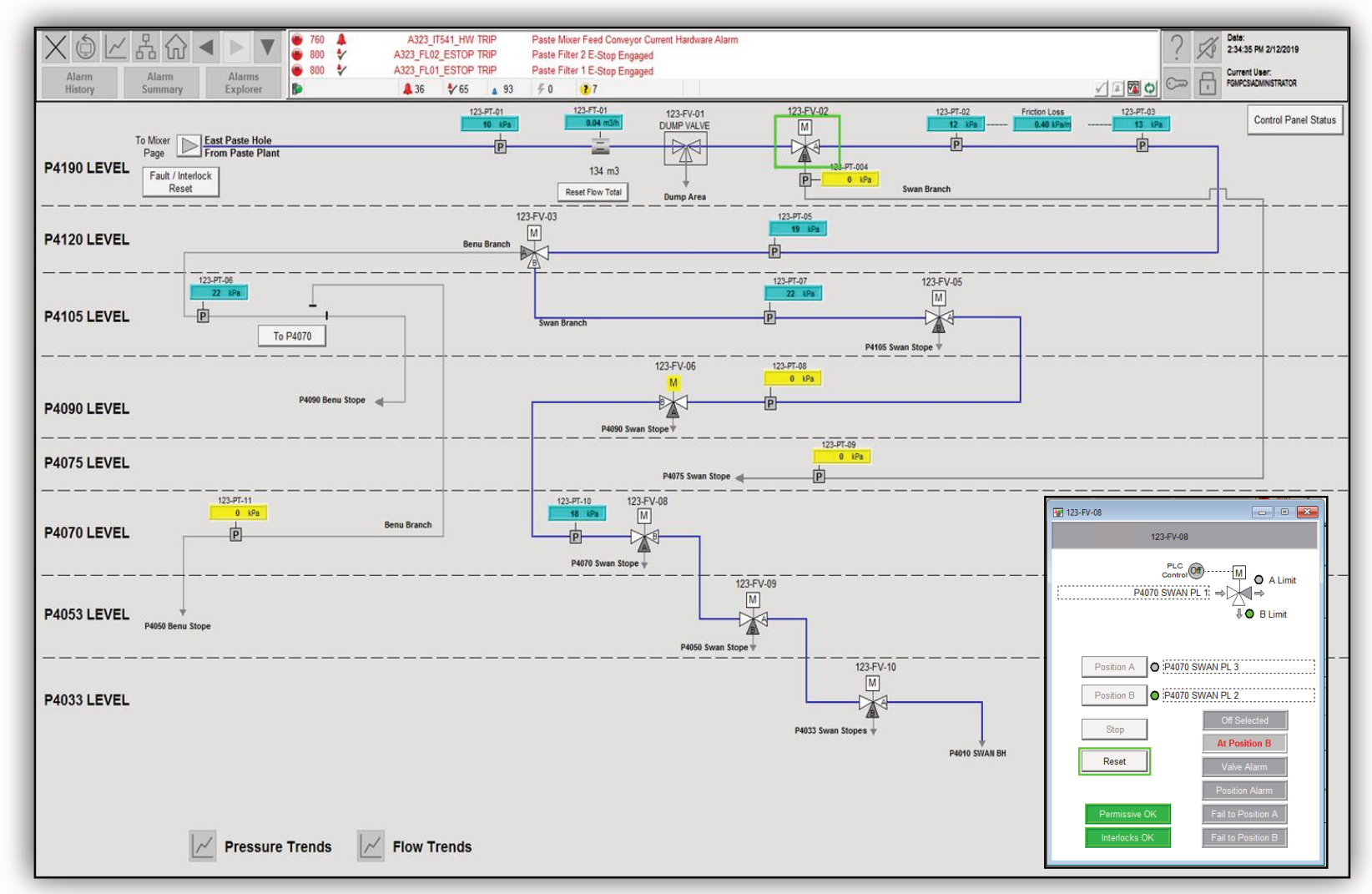

Figure 5 The plant operator can see the route of the piping highlighted in blue on the HMI display. Source: Kirkland Lake Gold, Toronto, Ontario

\section{Results and discussion}

The Victaulic $725 \mathrm{~S}$ diverter valve installed at the FGM delivered increased productivity, lower operating costs, and improved safety.

\subsection{Higher productivity, reduced operating costs}

Once a stope is filled, the time required to change the piping location to the next stope is critical. In reticulation systems where there are no diverter valves, the steps required include traveling to the lockout location, performing the lockout (sometimes this takes place on the surface), traveling to the switching location, manually switching the pipe, and finally traveling back to the lockout location and removing the locks. This can take a team of three paste operators anywhere from two to five hours, depending on the layout of the mine and the lockout procedure in place (Table 1). Using diverter valves eliminates these two to five hour delays, allowing paste filling to commence quickly. With the paste filling process expedited, mining can resume more rapidly, and ultimately, more ounces of gold can be mined each year.

Another time savings benefit is the substantial reduction of non-productive time. Adopting an automated process means the diverters can be used during shift changes when there is no access to the underground. Automation also frees the paste operators to perform other work during time that otherwise would have been spent manually managing the paste fill process.

The cumulative effect is reduced operating costs. In a typical lower cost mine such as FGM, the total cost to purchase and install a single diverter valve can be repaid in less than one month through increased ore production. 


\section{Table 1 Remote switchover process results in hours of labour savings}

\begin{tabular}{ll}
\hline \multicolumn{1}{c}{ Manual switchover } & $\begin{array}{c}\text { Time study } \\
\text { Remote actuated diverter valves }\end{array}$ \\
\hline $\begin{array}{l}\text { Travel to lockout location and perform } \\
\text { lockout }\end{array}$ & $\begin{array}{l}\text { Paste engineer directs plant operator (PO) to switch } \\
\text { diverter valve(s) to specified reticulation line number(s) } \\
\text { Travel to switching location }\end{array}$ \\
$\begin{array}{l}\text { Access hoist, crane or other heavy lifting } \\
\text { equipment }\end{array}$ & PO selects valve - actuates it to the direction specified \\
$\begin{array}{l}\text { Perform the manual switching operation } \\
\text { Travel back to the lockout location and } \\
\text { remove locks }\end{array}$ & $\begin{array}{l}\text { PO confirms correct position - indicated by limit switch } \\
\text { Po advises paste engineer that the switchover is }\end{array}$ \\
$\begin{array}{l}\text { complete } \\
\text { Estimated time to complete: } 2-5 \text { hours }\end{array}$ & $\begin{array}{l}\text { Paste engineer confirms on his HMI screen } \\
\text { Estimated time to complete: } 3-5 \text { minutes }\end{array}$ \\
\hline
\end{tabular}

\subsection{Improved safety}

In addition to improving profitability, automated diverter valves improve safety. An inherent safety feature of the Victaulic $725 \mathrm{~S}$ diverter valve is that all moving components and primary seals are contained within the valve body (Figure 6). Other diverter valves rely on exposed compression seals between the body and sliding plates or rotating discs, exposing operations personnel to high-pressure media spray and seal leakage if there is a failure during operation. In the unlikely event of seal wear on the Victaulic valve, all media remains contained within the valve body.

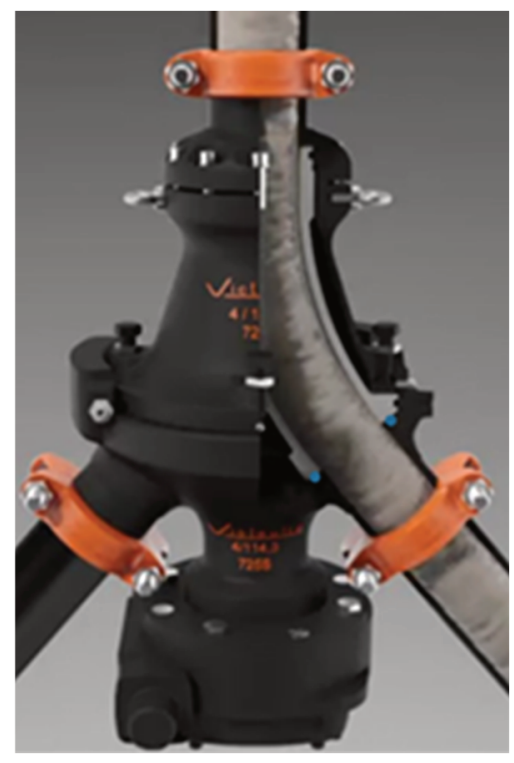

Figure 6 Series 725S cross-section. Source: Victaulic Co., Easton, Pennsylvania, USA

As these diverter valves can be actuated locally or from the surface control room, there is no need for a paste crew to travel to the valve location and work manually from the industrial tractor basket. Using these valves reduces the interaction of personnel and equipment, and eliminates the risk of personal injury.

The local actuation feature on the Victaulic diverter valve is beneficial when work is required on the reticulation system. Every time paste operators work on the paste line, some form of lockout is required. The operator can travel to the level where the work is to be performed, change the diverter control unit to local 
actuation, switch the valve away from the line to be worked on and lock out the actuator to isolate the line. This functionality provides the highest level of safety for operators because they can manage the process without relying on other personnel to ensure isolation.

\subsection{Additional benefits}

The FGM reticulation system includes a dedicated dump valve on the P4190L to dispose of the contents of the surface borehole into a dedicated collection area when required. The Victaulic $725 \mathrm{~S}$ diverter valve is rated for use as a dump valve under full pressure, so installing these valves on each level provides the additional benefit of being able to use the diverters for an emergency dump.

The cost of production delays caused by borehole blockages in mines varies depending on the production rate and the all-in sustaining costs (AISC) of the mine versus the current gold price. In broad terms, a month of lost production amounts to a few million US dollars at most mines. Also, there are additional costs for clearing borehole blockages, (or in extreme cases total borehole replacement), which can exceed USD 1 million. Therefore, a strategy of a reliable borehole dumping system and a backup surface borehole is used at most mines.

\subsection{Next generation}

Since the installation of the two-outlet valve at FGM, Victaulic has introduced a third outlet in the Series 725T valve. The third outlet permits 'traditional' alternating stope paste diversion thru the primary outlets, while offering a 'drain' outlet for flush water diversion or dumping of paste in the event of a blockage. The valves are fully automatable, allowing today's smart technology to operate the system from afar and monitor the system for pressure or flow anomalies, and have the valves react/respond to prevent system damage without human intervention.

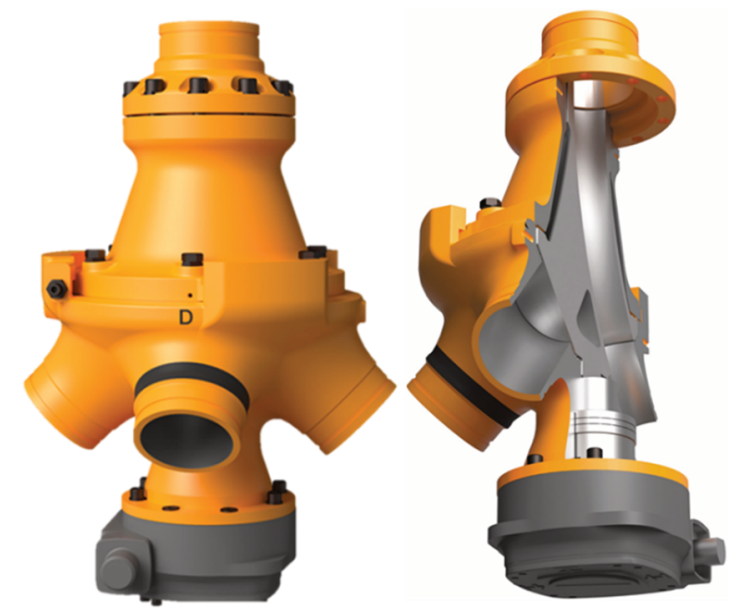

Figure 7 Series 725T four-way diverter valve. Source: Victaulic Co., Easton, Pennsylvania, USA

\section{Conclusion}

As backfill systems continue to evolve, so does the development of automated diverter valves. In recent years, systems have become larger, and paste pumped further, leading to the development of both larger sizes and higher-pressure valving than in the past. Valves are also being developed specifically for backfill, and not just adopted from the concrete pumping industry. These valves are more compact and safer to operate underground as they contain no unguarded externally rotating or sliding parts. To meet the evolving needs of mine operators, valves containing multiple outlets for paste diversion, paste evacuation, and flush water diversion, and valves capable of full automation and integration into intelligent systems are all conceived or being developed. 
Adopting the smart mine automated approach to backfilling at FGM has enabled more streamlined operations, increased productivity, and reduced safety risks. The new process allows the mine to produce more ounces per day and is improving profitability. The outlook for FGM is positive, with continuing exploration success in the Harrier Zone and downdip in the Phoenix Zone. Expansion of the underground paste reticulation system to these areas will be done as the ore zones are developed. If the stope geometries are similar to those in the Swan Zone, the current diverter valve usage model will be implemented on these levels based on successes to date.

The use of automated diverter valves on paste backfill is in line with Kirkland Lake Gold's emphasis on leveraging technology to promote productivity and move towards the goal of an interconnected mine. The installation at Fosterville has shown to improve the productivity of the underground paste crews and has contributed to increased revenue for the operation. Its success has led Kirkland Lake Gold to implement this backfill strategy at other facilities around the world. Most importantly, you cannot put a price on safety, and since the commissioning of the FGM paste system there have been no reportable injuries with respect to the switching of reticulation. 